\title{
Introduction to national innovation systems, social inclusion and development
}

\section{Gabriela Dutrénit and Judith Sutz}

Drawing on the seminal works of Freeman (1987), Lundvall (1992) and Nelson (1993), a vast literature on systems of innovation has flourished in recent years, using both a theoretical and an empirical approach. This has allowed the gradual strengthening of the concept. The theoretical path of construction has moved from the application of the concept nationwide to sectors and technologies, to regional and local levels, and then a new loop towards an enriched national focus.

The approach of the national system of innovation (NSI) centres on actors, institutions and their relationships, and contributes to a better understanding both of the intrinsic dynamics of innovation as well as its connections with development processes. Most of the existing literature worldwide analyses the institutional structures associated with the NSI, concentrating attention on their adequacy for generating an increase in innovative performance and competitiveness. This leads to the generation of science, technology and innovation (STI) policies that focus on improving innovation.

The link between knowledge, innovation and development has occupied Latin American thinking for decades. Many authors have used the NSI approach to picture the structure of actors and linkages for innovation in Latin American countries, and the inputs and outputs of the systems (Katz and Bercovitz, 1993, Cimoli, 2000; BID, 2001; Cassiolato et al., 2003; López, 2007; Dutrénit et al., 2010; Lemarchand, 2010; Llisterri and Pietrobelli, 2011). The conceptualisation of development has strongly integrated elements related to the quality of life that people can enjoy; development as an expansion of freedoms, according to Amartya Sen's approximation - which brings to the discussion what must be measured and how to measure that which characterises the advancement towards development. However, the literature based on the NSI approach has given less attention to those problems related to development, particularly to 
social inclusion, a central problem in the Latin American reality. Recently, social inclusion as an explicit objective of the NSI has been incorporated into the research agenda (Arocena and Sutz, 2012; Cozzens and Sutz, 2012; Johnson and Andersen, 2012; Couto et al., 2013).

The difficulties encountered by the development processes within the region on the one hand and new theoretical approaches on the other therefore necessitate a review of these fundamental links between knowledge, the NSI, development and social inclusion.

Latin America is a very heterogeneous region in terms of countries' levels of development and the maturity of their NSI. However, the region has a common feature that crosses from Patagonia to the Rio Grande and from the Pacific to the Atlantic: socially speaking, it is very uneven. After decades of development efforts, Latin America continues to be the most unequal region of the world. Major disparities persist within countries in welfare levels measured by per capita income and equality in income distribution. Even in countries that have reached the group of high-income economies and built a more articulated NSI, inequality prevails and large groups of the population remain excluded from the benefits of the development process.

This book is about inclusiveness, systems of innovation and development. It deals with some of the key questions in the region: How can the development process be accelerated and made able to include the less benefited sectors? How can NSIs that lead to inclusive development processes be built? What can we learn from the recent experiences of policy-making on these issues?

Inclusiveness is one of those concepts that seem self-evident, and for that very reason become fuzzy. As Max Weber once said, 'the apparently laborious definition of these concepts is an example that what is "self-evident" is rarely thought out clearly for the very reason that it appears obvious' (Weber, 1993: 98). It is important, then, to try to pass from self-evidence to a more explicit conceptualisation of inclusiveness. Given the wide scope of the concept, this book focuses on the question of what inclusiveness means when related to development.

It could be thought that after the depressing results of the Washington Consensus recommendations in Latin America, it would be unnecessary to recall that economic growth cannot be equated to development. Moreover, unequal economic growth plus corrective social policies may not lead to development either. The disruptive social effects of growth-led inequality are usually stronger and impact quicker than the remedy offered by social safety nets; this is at least the experience of many Latin American countries. But the conjunction of the self-evident truth that economic growth is needed for development, with the fact that economic growth in a globalised 
world has its own rules involving powerful interests, sometimes makes us forget that such growth should be a means for development and not an end in itself. When this is acknowledged - meaning simply that economic growth is not enough - the big question around what else is needed to reach a satisfactory level of development comes to the fore again.

One of the main sources of disappointment with the current state of affairs regarding development is the difficulty in lowering the levels of inequality within and between countries (Milanovic, 2011). Moreover, some outstanding situations of recent accelerated economic growth are accompanied by growing inequality, China being perhaps the clearest example. Economic growth, therefore, is supposedly necessary in order to include excluded people, but even when combined with restorative social policies it seems to be insufficient. This is perhaps why inclusive development is a concept that is receiving growing attention in such diverse settings as public policy, social movements, international organisations and non-governmental organisations (NGOs).

A primary point related to inclusive development is the double issue of all people being involved in decisions related to their well-being, and actions taken so that all people can enjoy the progress arising from the development process. As the United Nations Development Programme (UNDP) approach to inclusive development posits, 'Development can be inclusive - and reduce poverty - only if all groups of people contribute to creating opportunities, share the benefits of development and participate in decision-making. Inclusive development follows UNDP's human development approach and integrates the standards and principles of human rights: participation, non-discrimination and accountability' (UNDP, 2013).

From the perspective of systems of innovation, this definition poses an important challenge, because it stresses not only the sharing of the benefits of development, but also participation in shaping the process of development. As Amartya Sen (1999) puts it, for inclusive development to occur, people must be treated like agents and not as patients. But this means that the systems of innovation will need to take on board people with very different levels of education and skills, and design ways to allow these people to interact. Elinor Ostrom proposes a useful term for this: 'coproduction': 'By coproduction I mean the process through which inputs used to produce a good or service are contributed by individuals who are not "in" the same organisation' (Ostrom, 1996: 1073). The co-production of knowledge is a process that will not occur naturally; making room for people to co-produce the knowledge associated with the innovations effectively introduced in society is far from easy; it implies unorthodox ways of thinking, and a great deal of innovation in policy design. 
A second point related to inclusive development has to do with its political importance. The concept of 'inclusive development' is not only about poverty reduction but also about the reduction of inequalities. Albert Hirschman coined the expression 'the tunnel effect' to describe what happens in a society when inequality prevails. The argument goes as follows:

Imagine you are driving in a two-lane tunnel with both lanes headed in the same direction. All traffic is jammed as far as you can see - which is not very far. Suddenly the lane next to you starts to move. Initially you feel better, even though you are still stuck, because this signals to you that the jam has ended and your own lane will soon start moving, too. But after waiting at a standstill and watching the other lane moving for some time, your feelings change. You become envious and furious. You and others stuck in the lane begin to suspect foul play. You begin to search for a way to address the injustice of the situation by drastic action, including making illegal moves, such as crossing the double line that forbids moving from one lane to the other. (Muthoo, 2013)

Innovation can be the reason why one line starts moving while the other line is unable to move: innovation in unequal societies, particularly if related to the consumption of the well-off, can exacerbate inequalities (Rogers, 2003). In fact, businesses are not interested in a better income distribution; they look out for their own interest. In contrast, systems of innovation may stimulate the movements of both lines and contribute to the reduction of inequalities, but they must be designed for that aim. Again we find a policy dimension when inclusive development is associated with innovation.

A third point related to inclusive development has to do with structural change, particularly with changes in the role played by knowledge in society. One of the marks of underdevelopment is the weak level of knowledge demand stemming both from the private sector and from the public sphere. Inclusive development can only be achieved if knowledge production and innovation get stronger and are directed towards solving the types of problems that prevent people from being socially included. This requires a strong demand for such solutions. Given that the private effective demand will surely be weak in this case, public policy will have to be strong and sustainable to be able to start a virtuous circle in which knowledge production and innovation become intertwined around problems associated with social exclusion. As ECLAC (the Economic Commission for Latin America and the Caribbean) puts it, a structural change able to promote equality needs to place policy at the centre with its irreplaceable role of prioritising, orienting and coordinating (ECLAC, 2012). The space where innovations directed to inclusive development may flourish is a very special type of innovation system moulded by structural change of the type just mentioned. 
Drawing on this theoretical discussion, this book focuses on the issue of the building of NSIs that lead to inclusive development in Latin America. It focuses on the role of public policy, particularly in STI, in prioritising and coordinating towards inclusive development; the challenges this implies for policy design; the required structural change to build NSIs where knowledge is used for society; and the participation of stakeholders in this process. The policy dimension crosses all the country chapters; some of them directly related to concrete policy experiences of linking innovation and social inclusion, others as a more general reflection on routes of development that could lead to diminishing social exclusion.

The chapters on Colombia, Cuba, Peru and Uruguay explore the process of designing instruments aimed at fostering knowledge production and innovation for social inclusion. They are not committed to analysing specific sectors or problems known beforehand, they follow a country approach and look for the identification of problems as a first step. Such efforts explicitly recognise the need to involve a wide range of stakeholders in the designing process. In contrast, the chapter on Costa Rica follows a sectoral approach, and the system of innovation of the coffee and the palm oil sectors are studied to understand those innovations that led to a more inclusive dynamic. In the chapters on Argentina, Brazil and Mexico, a general analysis of the NSI for the whole productive system is provided, in trying to understand the changes in policy design that are needed for orienting the NSI towards inclusive development. The issues of structural change are dealt with in four chapters: one relates to the articulation of the micro and macro levels of innovation and productive policies; another explores relationships between growth patterns, NSIs and the welfare indicators of the economies; a third analyses the opportunities opened to the region by the extraordinary behaviour of the current demand for natural resources; and the last one considers the differences between the dynamics of the Argentinean and Canadian NSIs.

Chapter 1 provides a framework for analysing innovation and inclusive development as part of a wider process of knowledge democratisation. Rodrigo Arocena and Judith Sutz claim that in the global society established by capitalism, advanced knowledge is a fundamental infrastructure of the set of power dynamics; the most gravitating and destabilising productive dynamics have technological innovation as their main engine. These interconnected processes deeply impact upon who wins or loses in the distribution of benefits and damage of the expansion of science. The democratisation of knowledge therefore appears to be one of the necessary requirements for development, understood as an improvement in the quality of the material and spiritual life of people, seen not as patients but as agents, just as Amartya Sen sets out. The authors propose to rethink the 
subject of development, combining: (1) a normative approach based fundamentally on Sen's premises; (2) a factual-theoretical approach that takes into account the structural nature of inequality in the capitalist knowledge society; (3) a prospective approach, which explores the perspectives of advancing towards the normative horizon according to the restrictions and potentialities set by the facts; and finally (4) a propositional approach, centred on the democratisation of knowledge, an essential foundation for inclusive development. Although analytically separated, these four approaches are mutually interrelated and conditioned; based on their premises, social inclusion may become part of the aims and features of innovation policies and of the NSI.

Chapter 2 by Arturo Torres, Rosalba Casas, Claudia De Fuentes and Alexandre O. Vera-Cruz discusses the evolution of the Mexican system of innovation in light of its agents, interactions, governance and performance of the conceptions underlying the policies it has encouraged, and the opportunities and challenges for policies committed to inclusive development under prevailing economic policies. From the evidence observed, the chapter discusses how far the problems of poverty, marginalisation and exclusion can be addressed with the scientific, technological and innovation capacities built in the country, and what policies are needed to reorient these capacities and build new ones oriented towards social problems. Up to now, Mexico has followed the model of internationally prevailing STI policies, focusing on the exploitation of scientific and technological knowledge for economic growth. However, it is clear that this does not necessarily translate into development, social welfare and a more inclusive society. The NSI is facing a triple challenge, which is to develop its scientific and technological capabilities, stimulate innovation and business competitiveness, and meet social needs. The Mexican NSI has shown significant advances in performance, and the policies have moved gradually towards a systemic view. In addition, it is necessary to consider changes implemented in the system of incentives and the introduction of new tools to articulate the use of physical and human capabilities in research centres and universities with social demands associated with exclusion problems. The authors argue that governance schemes for social inclusion require greater participation of the beneficiaries, where knowledge users do not behave merely as passive agents or receivers of information, but are involved in the generation of solutions to their problems.

Chapter 3 discusses some of the essential features of the Brazilian NSI and the possibilities for addressing socio-environmental and developmental challenges, namely sustainability and inclusive development. Brazil had developed its science and technology (S\&T) infrastructure in a significant way by the $1950 \mathrm{~s}$, and from then on, significant positive results were 
achieved. The country has a growing, qualified human resource base, some of its universities and research institutions are internationally recognised, and in certain contexts, such as agricultural research, health, space and oil, cutting-edge research and development $(\mathrm{R} \& \mathrm{D})$ is taking place, including in the private sector. Also, local systems of innovation were created in different areas (agriculture, industry, culture and services) and are following virtuous paths of technological accumulation and innovation, which use different blends of local traditional knowledge combined with updated new information technologies. However, the evolution of the NSI has not articulated the logic of welfare and sustainability with the logic of economic development. José Eduardo Cassiolato, Helena Lastres and Maria Clara Soares argue that the State should exercise a fundamentally important role; not only for the development of active, selective and systemic policies aimed at strengthening the national techno-productive base, but also for ensuring convergence with social development objectives, overcoming backwardness in areas critical to combating social exclusion and attenuating regional inequalities.

Chapter 4, by Diana Suárez, Gabriel Yoguel, Verónica Robert and Florencia Barletta, analyses the evolution of the Argentinean NSI from a historical perspective. They claim that the recurrent strong economic, social and political turbulence in the last 100 years has influenced the productive and innovative behaviour of the agents, and marked structural patterns that determine a process that is not very virtuous. The authors analyse the organisations, institutions and linkages that determined the dynamics of accumulation of skills and growth in each period, and provide evidence at the level of businesses, sectors and local systems. They claim that the productive structure generated in these processes exhibits one of the main characteristics of developing countries: duality. There is, on the one hand, a set of activities mainly related to the highly competitive primary sector; and on the other, a manufacturing sector that is strongly heterogeneous, non-competitive, and dependent on foreign exchange from the primary sector. Both sectors are highly dependent on foreign technology. This structural duality, along with the political and distributive tensions it generates, prevented harmonious economic development and caused a set of swings and inconsistencies in the technology policy that fed the observed duality. The authors argue that despite the disappointing stylised facts, evidence of strong micro heterogeneity is the basis of the ability to identify success stories on which to base a national sustainable development strategy.

Colombia has included the concept of social innovation in its public policy agenda since 2010, a theme that has been present in the objectives of STI policies in the country for several years. Public agencies are trying 
to define their role around social innovation, identifying the various actors that can and should be involved in these processes. Based on this experience, Chapter 5, by Mónica Salazar, Marcela Lozano-Borda and Diana Lucio-Arias, discusses recent initiatives of Colciencias (an STI agency) designed to incorporate inclusive development in STI activities. It includes a description of the Colombian NSI and STI policies, showing the basis on which programmes have been developed and aimed at inclusive development. The chapter examines three pilot programmes developed by Colciencias focussed on integrating civil society to networks of production, using and appropriating knowledge, and contributing to the solution of social problems raised by the community. The authors claim that Colciencias's role should be focussed on the design of policies, programmes and instruments that promote capacity building of acquisition, use and disseminate knowledge and innovation, support the generation of knowledge that meets social problems, and set the scenes necessary for the proper use of the knowledge generated.

Chapter 6 discusses the experience of the Peruvian NSI in tackling objectives of inclusive development. Mario Bazán and Francisco Sagasti argue that social inclusion is an explicit objective of public policy and articulates the discourse between different instances of central and regional governments as well as local authorities. However, the Peruvian NSI is still highly fragmented and lacks the conditions necessary for promoting inclusive development in the country. In fact, the government has only recently begun to recognise that policies involving STI can contribute to generating greater inclusion. This chapter analyses innovation as a mechanism for inclusion and discusses three examples of interventions from public agencies and bodies, numerous private foundations, civil partnership organisations and academic institutions oriented to promote innovation focussed towards improving people's quality of life in situations of poverty, exclusion or vulnerability. The authors argue that social inclusion requires a comprehensive approach. Projects that are intended to reduce economic exclusion and have a positive impact in terms of greater social inclusion should be coordinated with projects oriented towards reducing cultural, political or environmental exclusion, as those issues could put what has been achieved at risk.

Chapter 7 analyses the central role that knowledge can and should have in the processes of supporting inclusive development. Santiago Alzugaray, María Goñi, Leticia Mederos and Sofía Robaina place particular emphasis on the direct contribution of knowledge in getting over problems that affect social inclusion, beyond contributions that can generate economic growth and a subsequent spillover towards the more disadvantaged sectors. Two programmes that incorporate social inclusion within their 
main objectives are analysed. The first is the National Strategic Plan for Science, Technology and Innovation introduced in 2010, which is based on a concept of double development that integrates economic growth and equality. This Strategic Plan is analysed in light of its application through policy instruments, examining the correspondence between discourse and practice, and the possible contribution - from the starting point of the programmatic basis and its concrete applications - for inclusive development in Uruguay. The second is the Programme for Research and Innovation Oriented Towards Social Inclusion introduced by the Universidad de la República. This chapter analyses the main achievements and lessons from the application of this instrument during the last decade, as well as the main difficulties encountered. In particular, it identifies relevant actors and links whose presence or absence can induce or limit the solution of problems that affect social inclusion with active participation of knowledge. The authors suggest a policy proposal aimed towards the formation of a national system of research and innovation oriented towards inclusive development. They argue for an active role played by the 'social' ministries when defining and implementing STI policy.

In Chapter 8, Jeffrey Orozco discusses the contribution of some institutional innovations for more inclusive development in the coffee and palm oil sectors in Costa Rica. Drawing on the idea that development is more than just growth, the author argues for the need to consider a variety of challenges (economic, social and environmental), as well as the trade-offs between them. He also argues that the focus on technological innovations is too limited to boost inclusive development, but that institutional changes must also take place. The debate on sustainable development makes clear the complexity of the process, not only because it includes new dimensions of analysis, but also because it puts in evidence the existence of trade-offs or conflicts in order to simultaneously reach different goals. These kinds of conflicts arise at the sector level as well. As well as many institutional aspects, the market structure in the sectors is a fundamental factor that determines the level of contribution of growth to inclusive development. Often, institutional changes are required for the 'new to business' or 'new to the market' innovations to contribute more to inclusive development, rather than 'new to the world' type innovations. In the cases of the coffee and palm oil sectors in Costa Rica, it is evident that some institutional innovations have historically contributed to these sectors becoming pillars for inclusive development, such as regulation of prices and a system of $\mathrm{R} \& \mathrm{D}$ with diffusion of technology for all participants.

In Chapter 9, Jorge Núñez Jover, Isvieysys Armas Marrero, Ariamnis Alcázar Quiñones and Galia Figueroa Alfonso state that from the 1990s, higher education in Cuba significantly oriented its efforts towards 
innovation. The so-called 'turn towards innovation' proposed to expand the role of higher education institutions in the economic recovery of the country and the solution of social problems. Towards 2006, the higher education institutions started to orient themselves more decidedly towards local development, through what has been called the 'turn towards territory'. This chapter explores the capacity of higher education to become a key agent in the deployment of networks that will allow the flow of knowledge and technologies that local development requires, transforming into pivots for emerging local systems of innovation. Through case study methodologies, the authors discuss a set of practices related to the production of sources of alternative energy, food production through agro-ecology, and the production of eco-materials for the construction of housing, always paying attention to the issue of whether these sociotechnical developments favour the objectives of inclusion, cohesion and social integration. The evidence shows the role of higher education institutions as technology promoters that help to solve social problems and connect directly with the daily necessities of people, supporting dynamics of inclusion, justice and well-being.

Jorge Katz and Rodrigo Astorga claim in Chapter 10 that growth theory is not much help when we come to examine through its lens why countries, industries or regions grow differently over time, and consider how to design and implement public policies to induce better long-term growth performance. Countries do not proceed along an equal growth path, making best use of the resources they have at their disposal at any point in time. Although a stylised equilibrium algorithm examining the 'sources' of growth in terms of factor accumulation and technical progress is in some sense helpful as a first approximation, it is nonetheless a far cry from what is needed - both analytically and for policy purposes - if we are to deal adequately with many of the questions posed by development economics. Besides a higher income per capita, in a very fundamental sense, economic development means changes in the structure of the economy; the building up of institutions, markets and technological capabilities, and the gradual 'construction' of new forms of interaction between economic agents, government authorities, and a large list of social organisations - universities, trade unions, political parties, and more - some of which do not even normally operate on the basis of conventional market rules. Not everything that we observe in the economy is the result of market processes. The gradual transformation of the production structure occurs naturally in the process of economic growth, such that keeping the economy expanding fast is an essential condition for it to become more sophisticated, structurally more complex and better positioned in the world marketplace. In this chapter, Jorge Katz and Rodrigo Ignacio Astorga argue that in spite 
of the improvement in economic performance attained by most Latin American countries over the past decade, they still lack an integrated and coherent macro-to-micro approach to policy formulation and implementation which would allow them to catch up with more developed industrial countries, in terms of both production efficiency and equity of access to the benefits of growth. This chapter compares the long-term performance of four very different economies - Korea, Ireland, Finland and Denmark which have done rather well in 'catching up' with the international productivity frontier; and four Latin American countries - Argentina, Brazil, Chile and Mexico - which have not done so well in this respect. In spite of the above, the latter countries show that a certain small fraction of their population has attained very significant gains from the transition to a more open and deregulated macroeconomic policy regime. Unfortunately, this has happened in the context of increasing social exclusion, insufficient provision of public goods, high incidence of poverty and environmental degradation; obviously a heavy intergenerational burden that will have to be taken care of in the not so distant future if democratic governance is to be sustained. Many of these questions cannot be adequately studied in the context of the 'mainstream' neoclassical explanation of what growth is all about, offered to us by the received theory of economic growth.

Chapter 11 examines the evolution of the Latin American economies between 1990 and 2011, and seeks to identify the relationships between growth patterns, systems of innovation and the welfare indicators of the economies, and whether the observed trajectories show the configuration of development regimes in the region in the long run. Gabriela Dutrénit, Juan Carlos Moreno-Brid and Martín Puchet identify two patterns of growth in the economies of the region that do not tend to converge during the period: a pattern of low growth that is characterised by a predominant contribution of exports to economic expansion, dynamic trade balance in relatively less deficit, and low rates of accumulation and growth of gross domestic product (GDP); and a high growth pattern that is characterised by a predominant contribution of investment in economic expansion, a dynamic trade balance, much less deficit in general, and larger accumulation and GDP growth rates. A relationship was detected between the relative weights of the components of demand in the growth of the different economies and the profile of their NSI. The low growth patterns led by exports have systems of innovation with less investment in STI and with a bias towards high-tech exports. In contrast, those led by investment have systems of innovation with more investment in STI, with a bias towards increasing the quantity of skilled personnel in STI. However, the growth patterns and the systems of innovation that characterise the different economies have a significant relationship (direct or inverse) neither to 
inequality, nor to the per capita GDP growth. In other words, the authors claim that welfare, as measured by the rise in per capita GDP and the more egalitarian distribution of income, is not mechanically associated with economic growth or with innovation. The system of innovation is immersed in the structural conditions of each country and the automatic transformation of innovation into growth and of growth into welfare is not observed in the Latin American experience. This comparative analysis has policy implications that question the recipes of policy packages that have prevailed in Latin America. It aims to contribute to the reflection on the improvements, setbacks and pending issues associated with the market reforms that were applied, in keeping with the Washington Consensus, and the economic policies that followed and drifted away from this orientation.

In Chapter 12, Jorge Niosi explores two countries with similarities in social indicators such as very low birth rates, low population density, fairly high life expectancy, high literacy rate, high immigration, and similar expenditure on education and health care in terms of GDP percentage. However, the countries differ in their economic performance. Niosi argues that institutions and institutional change are crucial to explain these trajectories, but key institutions are necessarily related to industry and STI institutions. Institution building in the area of STI in Argentina lags far behind that of Canada. He claims that during and after the Second World War, Argentina failed to pay attention to the institutions that should have increased its productivity through the incorporation of advanced human capital and technology, and the expansion of new sectors.

Chapter 13 explores the potential of natural resources-based networks for serving as platforms for development strategies. The main argument against such potential use is the claim that they have low technological dynamism. If that were the case, natural resources would indeed be incapable of serving as core of a development effort. This chapter by Carlota Pérez, Anabel Marín and Lizbeth Navas-Alemán holds that the changes induced by the ICT paradigm in the organisation of global corporations, the process of globalisation of production and the hyper-segmentation of markets have profoundly modified the conditions in all sectors, including natural resources. It analyses the recent and prospective forces driving innovation towards the 'decommoditisation' of the natural resources themselves as well as the conditions that are making networks of innovation more likely to be woven upstream and downstream as well as laterally from the natural resource base, constructing a production and innovation network which is taken as the unit of analysis. Finally, it looks at the conditions under which full advantage could be taken of this potential for both development and poverty alleviation strategies. The chapter uses evidence from case studies to illustrate how some of these transformations 
are already taking place in Latin America. The authors believe that this ensemble of views and perspectives will provide the reader with concepts, approaches and evidences useful to contribute individually to the pursuit of inclusive development.

\section{ACKNOWLEDGEMENTS}

This book was funded by the National Science and Technology Council (CONACYT) in 2012 under the project name 'Construction of the Latin American Network for Learning, Capabilities and STI Policies for Inclusive Development' (LALICS) (project 189070), and developed by the Universidad Autónoma Metropolitana. We are grateful for the invaluable support received from M.Phil. Mariana de Heredia and Dr Marcela Suárez at different stages of the project.

\section{REFERENCES}

Arocena, R. and Sutz, J. (2012), 'Research and innovation policies for social inclusion: is there an emerging pattern?', in Lastres, H.M.M., Pietrobelli, C., Caporalli, R., Couto Soares, M.C. and Pessoa de Matos, M. (eds), A nova geração de políticas de desenvolvimento productivo, sustentabildade social e ambiental, Brasilia: BID/BNDES/SESI/CNI, pp. 101-113.

BID (2001), 'Sistemas de innovación en América Latina', in Competitividad: el motor de crecimiento, Informe 2001, Santiago de Chile: BID, pp. 243-259.

Cassiolato, J.H., Lastres, H.M.M. and Maciel, M.L. (eds) (2003), Systems of Innovation and Development Evidence from Brazil, Cheltenham, UK and Northampton, MA, USA: Edward Elgar.

Cimoli, M. (ed.) (2000), Developing Innovation Systems, Mexico in the Global Context, London: Pinter.

Couto Soares, M.C., Scerri, M. and Maharajh, R. (eds) (2003), Inequality and Development Challenges: BRICS National Systems of Innovation, New Delhi: Routledge.

Cozzens, S. and Sutz, J. (2012), 'Innovation in informal settings: a research agenda', available at http://www.idrc.ca/EN/Resources/Publications/Pages/ArticleDetails. aspx?PublicationID=1130.

Dutrénit, G., Capdeville, M., Corona, J., Puchet, M., Santiago, F. and Vera-Cruz, A. (2010), El Sistema Nacional de Innovación Mexicano: Instituciones, Políticas, Desempeño y Desafios, Mexico City: UAM-X/ Textual.

ECLAC (2012), Structural Change for Equality: An Integrated Approach to Development, ECLAC: Santiago de Chile.

Freeman, C. (1987), Technology, Policy and Economic Performance: Lessons from Japan, London: Pinter Publishers.

Johnson, B. and Andersen, A. (2012), 'Learning, innovation and inclusive development', Globelics Thematic report No. 1, Aalborg. 
Katz, J. and Bercowitz, N. (1993), 'National systems of innovation supporting advance in industry: the case of Argentina', in Nelson, R. (ed.), National Systems of Innovation. A Comparative Analysis, New York: Oxford University Press, pp. 451-475.

Lemarchand, G. (ed.) (2010), 'Sistemas nacionales de ciencia, tecnología e innovación', Estudios y documentos de política científica en ALC, 1, UNESCO.

Llisterri, J.J. and Pietrobelli, C. (eds) (2011), Los Sistemas Regionales de Innovación en América Latina, Washington, DC: BID.

López, A. (2007), Desarrollo Económico y Sistema Nacional de Innovación en la Argentina, Buenos Aires: Buenos Aires, Consejo Profesional de Ciencias Económicas de la Ciudad Autónoma de Buenos Aires.

Lundvall, B.-A. (1992), National Systems of Innovation: Towards a Theory of Innovation and Interactive Learning, London: Pinter.

Milanovic, B. (2011), The Haves and the Have-Nots: A Brief and Idiosyncratic History of Global Inequality, New York: Basic Books.

Muthoo, A. (2013), 'The tunnel effect: a parable for our economic times', available at http://www.publicserviceeurope.com/article/3151/the-tunnel-effect-a-parablefor-our-economic-times\#ixzz2MlaRzJA9.

Nelson, R.R. (ed.) (1993), National Innovation Systems: A Comparative Analysis, New York: Oxford University Press.

Ostrom, E. (1996), 'Crossing the great divide: coproduction, synergy, and development', World Development, 24 (6), 1073-1087.

Rogers, E. (2003), The Sources of Innovation, New York: Free Press.

Sen, A. (1999), Development as Freedom, New York: Oxford University Press.

UNDP (2013), 'Inclusive development', available at http://www.undp.org/content/ undp/en/home/ourwork povertyreduction/focus_areas/focus_inclusive_develop ment/.

Weber, M. (1993), Basic Concepts in Sociology, New York: Citadel Press. 